\title{
DESKRIPSI PENILAIAN MASYARAKAT TENTANG DAMPAK PERKEMBANGAN KAWASAN TERBANGUN BERDASARKAN PERTIMBANGAN MULTI ASPEKDI KOTA YOGYAKARTA
}

\author{
Ani Apriani ${ }^{1}$, Septiana Fathurrohmah ${ }^{2}$, Sri Haryatmi ${ }^{3}$, Danardono ${ }^{4}$ \\ ${ }^{1}$ Jurusan TeknikGeologi, ${ }^{2}$ Jurusan TeknikPerencanaan Wilayah dan Kota, ${ }^{3,4}$ Jurusan \\ Matematika \\ ${ }^{1,2}$ Sekolah TinggiTeknologiNasional,JalanBabarsari, Catur Tunggal, Depok, Sleman, \\ Yogyakarta \\ ${ }^{3,4}$ UniversitasGadjahMada, Bulaksumur Yogyakarta 55281 \\ ${ }^{1}$ aniapriani@sttnas.ac.id, ${ }^{2}$ septiana@sttnas.ac.id,

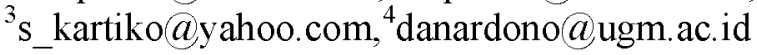

\begin{abstract}
The increasing of development in Yogyakarta City gives rise to controversy. Physical development-oriented activities are considered tend to pursue economic benefits with less regard for social and environmental impacts. The purpose of this paper is to describe the community's assessment of the impact of regional development on environmental, socio-cultural and economic aspects. This research uses quantitative descriptive approach as the method. There are 128 respondents $(32,0 \%)$ state that development of built-up area trigger negative impact to the environmental aspect whereas 272 respondents (68\%) state no negative impact. On socio-cultural aspect, 83 respondents $(20,8 \%)$ stated that there are negative impact and 317 respondents $(79,2 \%)$ state that there aren' $t$ negative impact from development of built-up area. On third aspect, there are 147 respondents $(36,8 \%)$ state that development of built-up area trigger negative impact to the economic aspect whereas 253 respondents (63,2\%) state no negative impact.
\end{abstract}

Keyword: Impact, City, Development, Community, Perseption.

Abstrak

Meningkatnya aktivitas pembangunan di Kota Yogyakarta menimbulkan pro dan kontra dalam masyarakat. Hal tersebut dikarenakan aktivitas pembangunan yang berorientasi fisik dianggap cenderung mengejar keuntungan ekonomi dengan kurang mengindahkan dampak social dan lingkungan. Tujuan dari makalah ini akan mendeskripsikan penilaian masyarakat tentang dampak perkembangan kawasan berdasarkan pertimbangan aspek lingkungan, sosial budaya dan ekonomi. Metodologi yang digunakan dalam penelitian ini berupa penelitian deskriptif kuantitatif. Sebanyak 128 orang $(32,0 \%)$ menyatakan perkembangan kawasan terbangun memiliki dampak negative terhadap aspek lingkungan dan sebanyak 272 orang (68\%) menyatakan perkembangan kawasan terbangun tidak memiliki dampak negative terhadap lingkungan. Sebanyak 83 orang $(20,8 \%)$ menyatakan perkembangan kawasan terbangun memiliki dampak negative terhadap aspek social budaya dan sebanyak 317 orang $(79,2 \%)$ menyatakan perkembangan kawasan terbangun tidak memiliki dampak negative terhadap aspek social budaya. Sebanyak 147 orang $(36,8 \%)$ menyatakan perkembangan kawasan terbangun memiliki dampak negative terhadap aspek ekonomi dan sebanyak 253 orang $(63,2 \%)$ menyatakan perkembangan kawasan terbangun tidak memiliki dampak negative terhadap aspek ekonomi.

Kata Kunci : Kota, Dampak, Pembangunan, Masyarakat, Persepsi. 


\section{Latar Belakang Masalah}

Yogyakarta merupakan Kota kedua menjadi destinasi wisata setelah Bali. Seperti tercantum dalam statistik DIY 2015 bahwa Visi pembangunan pariwisata DIY 2012- 2025 adalah mewujudkan Yogyakarta sebagai destinasi wisata berkelas dunia, memiliki keunggulan saing dan banding, berwawasan budaya, berkelanjutan, mampu mendorong pembangunan daerah dan berbasis kerakyatan sebagai pilar utama perekonomian (Perda DIY No 1, 2012). Untuk mewujudkan visi tersebut maka strategi yang ditempuh adalah mengarahkan dan memprioritaskan pariwisata sebagai bidang prioritas pembangunan kedua setelah bidang pendidikan. Hal ini menjadi bahan acuan dan lahan bagi pelaku ekonomi dan investor untuk menanamkan investasinya di kota Yogyakarta. Alhasil pada tahun-tahun terakhir ini berkembang pesat proyek-proyek pembangunan hotel, mall, apartemen dan kondotel yang menyebar di Yogyakarta. Pertumbuhan hotel dari mulai tahun $2004-2014$ digambarkan dalam tabel 1 berikut.

Tabel 1. Jumlah Hotel di DIY Menurut Jenis Hotel Tahun 2009-2014(Sumber: BPS DIY, 2015)

\begin{tabular}{|c|c|c|c|c|c|c|c|}
\hline \multirow{2}{*}{$\begin{array}{c}\text { Kategori } \\
\text { Hotel }\end{array}$} & \multirow{2}{*}{$\begin{array}{c}\text { Jenis } \\
\text { Akomodasi }\end{array}$} & \multicolumn{6}{|c|}{ Tahun } \\
\hline & & 2009 & 2010 & 2011 & 2012 & 2013 & 2014 \\
\hline \multirow[t]{3}{*}{ Bintang } & Akomodasi & 34 & 36 & 41 & 54 & 61 & 71 \\
\hline & Kamar & 3373 & 3631 & 3953 & 5150 & 5801 & 6864 \\
\hline & Tempat tidur & 5633 & 5807 & 6389 & 8171 & 9280 & 10725 \\
\hline \multirow{3}{*}{$\begin{array}{l}\text { Non } \\
\text { bintang }\end{array}$} & Akomodasi & 1098 & 1098 & 1063 & 1100 & 1109 & 1067 \\
\hline & Kamar & 12519 & 12519 & 12407 & 13309 & 13547 & 13624 \\
\hline & Tempat tidur & 18293 & 18293 & 18586 & 21720 & 21549 & 19860 \\
\hline
\end{tabular}

Dari data tersebut total hotel pada tahun 2014 ada 1170 hotel. Sedangkan jumlah mall hingga Desember 2014 terdapat enam buah yang beroperasi. Jumlah tersebut akan bertambah dengan kehadiran enam pusat belanja baru yang beroperasi tahun ini hingga 2018. Dengan demikian proses pembangunan yang terjadi di kota Yogyakarta sudah jauh diatas kapasitas.

Secara garis besar positifnya dari pembangunan adalah peningkatan fasilitas untuk dimanfaatkan oleh masyarakat dan tidak kalah pentingnya adalah pendapatan daerah yang meningkat. Akan tetapi dampak negatif dari pembangunan tersebut juga besar terhadap masyarakat sekitar. Hal ini dibuktikan dengan dampak lingkungan, sosiokultural dan ekonomi yang terjadi akibat dari pembangunan. 


\section{Metodologi Penelitian}

\subsection{Pendekatan Penelitian}

Pendekatan penelitan merupakan pendekatan kuantitatif dengan mengunakan uji deskriptif untuk melihat penilaian masyarakat mengenai dampak perkembangan kawasan terbangun berdasarkan pertimbangan multi aspek.

\subsection{Populasi dan Sampel}

Populasi penelitian yaitu masyarakat Kota Yogayakarta. Berdasarkan data BPS Kota Yogyakarta. Jumlah penduduk berdasarkan sensus penduduk Kota Togyakarta tahun 2013 sebesar 404.692 orang. Dari jumlah tersebut penentuan sampel penelitian menggunakan rumus Slovin (Riduwan, 2005) sehingga menghasilkan jumlah sampel yang diteliti sebanyak 400 orang. Jumlah sampel tersebut dibatasi usia yaitu lebih dari 17 tahun dengan KTP asli Kota Yogyakarta.

\subsection{Metode dan Prosedur Pengumpulan Data}

Sumber data dalam penelitian ini dibagi menjadi dua yaitu data primer dan data sekunder. Metode pengumpulan data primer mengunakan kuesioner yang diuji terlebih dahulu validitas dan reliabilitasnya. Sedangkan data sekunder merupakan data pendukung hasil penelitian berupa literatur, data yang bersumber dari BPS dan pemerintah daerah setempat.

\subsection{Metode Analisis Data}

Analisis yang digunakan dalam perhitungan ini terdiri dari dua bagian. Bagian pertama merupakan analisa data yang sifatnya deskriptif yang bertujuan untuk mendeskripsikan penilaian masyarakat tentang dampak kawasan terbangun.

\section{Hasil dan Pembahasan}

3.1 Dampak Terhadap Aspek Lingkungan

Aspek lingkungan yang diteliti dalam penelitian ini meliputi kuantitas air, kualitas air, penyerapan air, suhu udara, polusi udara, iklim, kebisingan dan tata guna lahan. Deskripsi dari masing-masing indikator tersebut disajikan dalam tabel 2 berikut.

Tabel 2. Distribusi Frekuensi Berdasarkan Indikator Aspek Lingkungan

(Sumber: Data primer, 2017)

\begin{tabular}{|c|c|c|c|c|}
\hline No & Indikator & Kategori & Frekuensi & Persentase \\
\hline \multirow{6}{*}{1} & \multirow{6}{*}{ Kuantitas Air } & $\begin{array}{l}\text { Terjadi Penurunan Air Sumur } \\
\text { lebih dari } 6 \text { meter }\end{array}$ & 14 & $3,5 \%$ \\
\hline & & Terjadi Penurunan 5-6 Meter & 13 & $3,3 \%$ \\
\hline & & Terjadi penurunan 3 - 4 meter & 27 & $6,8 \%$ \\
\hline & & Terjadi Penurunan 1 - 2 meter & 64 & $16,0 \%$ \\
\hline & & $\begin{array}{l}\text { Tidak Terjadi Penurunan Air } \\
\text { Sumur }\end{array}$ & 282 & $70,5 \%$ \\
\hline & & Total & 400 & $100,0 \%$ \\
\hline \multirow{4}{*}{2} & \multirow{4}{*}{ Kualitas Air } & Sangat Rendah & 1 & $0,3 \%$ \\
\hline & & Cukup Rendah & 20 & $5,0 \%$ \\
\hline & & Baik & 379 & $94,8 \%$ \\
\hline & & Total & 400 & $100,0 \%$ \\
\hline \multirow{6}{*}{3} & \multirow{6}{*}{ Penyerapan Air } & Terjadi lebih dari 4 Genangan & 3 & $0,8 \%$ \\
\hline & & Terdapat 4 Titik Genangan & 3 & $0,8 \%$ \\
\hline & & Terdapat 3 titik genangan & 4 & $1,0 \%$ \\
\hline & & Terdapat 2 titik genangan & 29 & $7,3 \%$ \\
\hline & & Penyerapan air baik & 361 & $90,3 \%$ \\
\hline & & Total & 400 & $100,0 \%$ \\
\hline
\end{tabular}




\begin{tabular}{|c|c|c|c|c|}
\hline \multirow{4}{*}{4} & \multirow[t]{4}{*}{ Suhu Udara } & Panas Sekali & 170 & $42,5 \%$ \\
\hline & & Cukup Panas & 164 & $41,0 \%$ \\
\hline & & Sejuk & 66 & $16.5 \%$ \\
\hline & & Total & 400 & $100,0 \%$ \\
\hline \multirow{4}{*}{5} & \multirow{4}{*}{ Polusi Udara } & Sangat Berpolusi & 83 & $20,8 \%$ \\
\hline & & Cukup berpolusi & 182 & $45,5 \%$ \\
\hline & & Tidak Berpolusi & 135 & $33,8 \%$ \\
\hline & & Total & 400 & $100,0 \%$ \\
\hline \multirow{4}{*}{6} & \multirow{4}{*}{ Iklim } & Iklim sulit diprediksi & 170 & $42,5 \%$ \\
\hline & & Iklim kadang bisa diprediksi & 177 & $44,3 \%$ \\
\hline & & Iklim bisa diprediksi & 53 & $13.3 \%$ \\
\hline & & Total & 400 & $100,0 \%$ \\
\hline \multirow{4}{*}{7} & \multirow{4}{*}{ Kebisingan } & Sangat Bising & 94 & $23,5 \%$ \\
\hline & & Cukup Bising & 174 & $43,5 \%$ \\
\hline & & Tidak bising & 132 & $33.0 \%$ \\
\hline & & Total & 400 & $100,0 \%$ \\
\hline \multirow{6}{*}{8} & \multirow{6}{*}{ Tata Guna Lahan } & $\begin{array}{l}\text { Terdapat lebih dari } 3 \text { tempat } \\
\text { y ang beralih fungsi }\end{array}$ & 53 & $13,3 \%$ \\
\hline & & $\begin{array}{l}\text { Terdapat } 3 \text { tempat yang beralih } \\
\text { fungsi }\end{array}$ & 10 & $2,5 \%$ \\
\hline & & $\begin{array}{l}\text { Terdapat } 2 \text { tempat yang beralih } \\
\text { fungsi }\end{array}$ & 9 & $2,3 \%$ \\
\hline & & $\begin{array}{l}\text { Terdapat } 1 \text { tempat yang beralih } \\
\text { fungsi }\end{array}$ & 27 & $6,8 \%$ \\
\hline & & $\begin{array}{l}\text { Tidak ada yang beralih fungsi } \\
\text { dari lahan pertanian menjadi } \\
\text { permukiman }\end{array}$ & 301 & $75,3 \%$ \\
\hline & & Total & 400 & $100,0 \%$ \\
\hline \multirow{3}{*}{9} & \multirow{3}{*}{$\begin{array}{l}\text { Ketersediaan Ruang } \\
\text { Terbuka Hijau }\end{array}$} & Tidak ada & 287 & $71,8 \%$ \\
\hline & & Ada & 113 & $28,3 \%$ \\
\hline & & Total & 400 & $100,0 \%$ \\
\hline
\end{tabular}

Secara umum dampak perkembangan kawasan terbangun terhadap aspek lingkungan disajikan dalam tabel 3 berikut.

Tabel 3. Distribusi Frekuensi Dampak Perkembangan Kawasan Terbangun BerdasarkanAspek Lingkungan di Kota Yogyakarta Tahun 2017

(Sumber: data primer diolah, 2017)

\begin{tabular}{|l|c|c|}
\hline \multicolumn{1}{|c|}{ Kategori } & Jumlah & Persentase \\
\hline Sangat Baik & 24 & $6.0 \%$ \\
\hline Baik & 139 & $34.8 \%$ \\
\hline Sedang & 109 & $27.3 \%$ \\
\hline Buruk & 86 & $21.5 \%$ \\
\hline Sangat Buruk & 42 & $10.5 \%$ \\
\hline Total & 400 & $100.0 \%$ \\
\hline
\end{tabular}


Berdasarkan tabel 3 di atas, yang menjawab bahwa terdapat dampak negatif dari perkembangan kawasan terbangun terhadap aspek lingkungan yang diwakili oleh kategori buruk dan sangat buruk yaitu 128 orang $(32,0 \%)$ dan sebanyak 272 orang $(68 \%)$ yang menjawab bahwa tidak terdapat dampak negatif terhadap aspek lingkungan yang diwakili kategori sangat baik, baik dan sedang.

3.2 Dampak Terhadap Aspek Sosial Budaya

Aspek sosial budaya yang diteliti dalam penelitian ini meliputi kelembagaan masyarakat, interaksi antar masyarakat, kebudayaan masyarakat, perilaku hidup masyarakat dan kualitas hidup masyarakat. Deskripsi dari masing-masing indikator tersebut disajikan dalam tabel 4 berikut.

Tabel 4. Distribusi Frekuensi Berdasarkan Indikator Aspek Sosial Budaya (Sumber: Data primer, 2017)

\begin{tabular}{|c|c|c|c|c|}
\hline No & Komponen & Kategori & Frekuensi & Persentase \\
\hline \multirow{4}{*}{1} & \multirow{4}{*}{$\begin{array}{c}\text { Kelembagaan } \\
\text { Masy arakat }\end{array}$} & $\begin{array}{l}\text { Sama sekali tidak aktif di } \\
\text { kelembagaan masyarakat }\end{array}$ & 62 & $15,5 \%$ \\
\hline & & $\begin{array}{l}\text { Kurang Aktif di kelembagaan } \\
\text { masyarakat }\end{array}$ & 72 & $18,0 \%$ \\
\hline & & $\begin{array}{l}\text { Aktif di kelembagaan } \\
\text { masyarakat }\end{array}$ & 266 & $66,5 \%$ \\
\hline & & Total & 400 & $100,0 \%$ \\
\hline \multirow{4}{*}{2} & \multirow{4}{*}{$\begin{array}{l}\text { Interaksi Antar } \\
\text { Masyarakat }\end{array}$} & $\begin{array}{l}\text { Interaksi antar masyarakat } \\
\text { Sangat Rendah }\end{array}$ & 23 & $5,8 \%$ \\
\hline & & $\begin{array}{l}\text { Interaksi antar masyarakat } \\
\text { Cukup Rendah }\end{array}$ & 101 & $25.3 \%$ \\
\hline & & $\begin{array}{l}\text { Interaksi antar masyarakat } \\
\text { Tinggi }\end{array}$ & 276 & $69,0 \%$ \\
\hline & & Total & 400 & $100,0 \%$ \\
\hline \multirow{4}{*}{3} & \multirow{4}{*}{$\begin{array}{l}\text { Kebudayaan } \\
\text { Masyarakat }\end{array}$} & $\begin{array}{l}\text { Masyarakat tidak Melestarikan } \\
\text { budaya }\end{array}$ & 149 & $37,3 \%$ \\
\hline & & $\begin{array}{l}\text { Masyarakat jarang Melestarikan } \\
\text { budaya }\end{array}$ & 169 & $42,3 \%$ \\
\hline & & $\begin{array}{l}\text { Masyarakat tetap Melestarikan } \\
\text { budaya }\end{array}$ & 82 & $20,5 \%$ \\
\hline & & Total & 400 & $100,0 \%$ \\
\hline \multirow{4}{*}{4} & \multirow{4}{*}{$\begin{array}{l}\text { Perilaku Hidup } \\
\text { Masyarakat }\end{array}$} & $\begin{array}{l}\text { Perilaku hidup masyarakat } \\
\text { Kurang Baik }\end{array}$ & 6 & $1,5 \%$ \\
\hline & & $\begin{array}{l}\text { Perilaku hidup masyarakat } \\
\text { Cukup Baik }\end{array}$ & 39 & $9,8 \%$ \\
\hline & & Perilaku hidup masyarakat Baik & 355 & $88,8 \%$ \\
\hline & & Total & 400 & $100,0 \%$ \\
\hline \multirow{4}{*}{5} & \multirow{4}{*}{$\begin{array}{l}\text { Kualitas Hidup } \\
\text { Masyarakat }\end{array}$} & $\begin{array}{l}\text { Kualitas hidup masyarakat } \\
\text { Sangat Rendah }\end{array}$ & 2 & $0,5 \%$ \\
\hline & & $\begin{array}{l}\text { Kualitas hidup masyarakat } \\
\text { cukup Rendah }\end{array}$ & 48 & $12,0 \%$ \\
\hline & & $\begin{array}{l}\text { Kualitas hidup masyarakat } \\
\text { Tinggi }\end{array}$ & 350 & $87,5 \%$ \\
\hline & & Total & 400 & $100,0 \%$ \\
\hline
\end{tabular}

Secara umum dampak perkembangan kawasan terbangun terhadap aspek lingkungan disajikan dalam tabel 5 . 
Tabel 5. Distribusi Frekuensi Dampak perkembangan kawasan Terbangun BerdasarkanAspek Sosial Budaya di Kota Yogyakarta Tahun 2017

(Sumber : data primer diolah, 2017)

\begin{tabular}{|l|c|c|}
\hline \multicolumn{1}{|c|}{ Kategori } & Jumlah & Persentase \\
\hline Baik & 133 & $33.3 \%$ \\
\hline Sedang & 184 & $46.0 \%$ \\
\hline Buruk & 49 & $12.3 \%$ \\
\hline Sangat Buruk & 34 & $8.5 \%$ \\
\hline Total & 400 & $100.0 \%$ \\
\hline
\end{tabular}

Berdasarkan tabel 5, yang menjawab bahwa terdapat dampak negatif dari perkembangan kawasan terbangun terhadap aspek sosial budaya yang diwakili oleh kategori buruk dan sangat buruk yaitu 83 orang $(20,8 \%)$ dan sebanyak 317 orang $(79,2 \%)$ yang menjawab bahwa tidak terdapat dampak negatif terhadap aspek sosial budaya yang diwakili kategori baik dan sedang. Dampak kawasan terbangun dari aspek sosial budaya sebagaimana tabel di atas tidak terdapat kategori sangat baik $(0 \%)$.

\subsection{Dampak Terhadap Aspek Ekonomi}

Aspek ekonomi yang diteliti dalam penelitian ini meliputi perpindahan penduduk ke dalam kota yogyakarta, penyerapan tenaga kerja, berkembanganya struktur ekonomi, pendapatan masyarakat, pengeluaran masyarakat, perubahan pekerjaan masyarakat, kondisi kesehatan masyarakat, penambahan fasilitas pendidikan, penambahan fasilitas beribadah, dan penambahan fasilitas kesehatan. Deskripsi dari masing-masing indikator tersebut disajikan dalam tabel 6.

Tabel 6. Distribusi Frekuensi Berdasarkan Indikator Aspek Ekonomi (Sumber : data primer, 2017)

\begin{tabular}{|c|c|c|c|c|}
\hline No & Komponen & Kategori & Frekuensi & Persentase \\
\hline \multirow{3}{*}{1} & \multirow{3}{*}{$\begin{array}{c}\text { Perpindahan } \\
\text { penduduk Ke dalam } \\
\text { Kota Yogyakarta }\end{array}$} & Perpindahan dari daerah lain & 109 & $27,3 \%$ \\
\hline & & Asli Jogja & 291 & $72,8 \%$ \\
\hline & & Total & 400 & $100,0 \%$ \\
\hline \multirow{3}{*}{2} & \multirow{3}{*}{$\begin{array}{l}\text { Penyerapan tenaga } \\
\text { kerja }\end{array}$} & $\begin{array}{l}\text { Tidak Berkerja di salah satu } \\
\text { proyek pembangunan di Kota } \\
\text { Yogyakarta }\end{array}$ & 109 & $27.3 \%$ \\
\hline & & $\begin{array}{l}\text { Bekerja di salah satu proyek } \\
\text { pembangunan di Kota } \\
\text { Yogyakarta }\end{array}$ & 291 & $72.8 \%$ \\
\hline & & Total & 400 & $100.0 \%$ \\
\hline \multirow{5}{*}{3} & \multirow{5}{*}{$\begin{array}{l}\text { Berkembanganya } \\
\text { Struktur Ekonomi }\end{array}$} & $\begin{array}{l}\text { Terdapat peningkatan } 1 \text { sarana } \\
\text { ekonomi }\end{array}$ & 192 & $48,0 \%$ \\
\hline & & $\begin{array}{l}\text { Terdapat peningkatan } 2 \text { sarana } \\
\text { ekonomi }\end{array}$ & 110 & $27,5 \%$ \\
\hline & & $\begin{array}{l}\text { Terdapat peningkatan } 3 \text { sarana } \\
\text { ekonomi }\end{array}$ & 6 & $1,5 \%$ \\
\hline & & $\begin{array}{l}\text { Terdapat peningkatan } 4 \text { sarana } \\
\text { ekonomi }\end{array}$ & 92 & $23,0 \%$ \\
\hline & & Total & 400 & $100,0 \%$ \\
\hline \multirow{5}{*}{4} & \multirow{5}{*}{$\begin{array}{l}\text { Pendapatan } \\
\text { Masyarakat }\end{array}$} & Tidak meningkat & 201 & $50,3 \%$ \\
\hline & & cukup meningkat (1-5\%) & 142 & $35,5 \%$ \\
\hline & & Meningkat (6-20\%) & 47 & $11,8 \%$ \\
\hline & & Meningkat dratis $(>20 \%)$ & 10 & $2,5 \%$ \\
\hline & & Total & 400 & $100,0 \%$ \\
\hline
\end{tabular}




\begin{tabular}{|c|c|c|c|c|}
\hline \multirow{5}{*}{5} & \multirow{5}{*}{$\begin{array}{l}\text { Pengeluaran } \\
\text { Masyarakat }\end{array}$} & $\begin{array}{l}\text { Pengeluaran meningkat lebih } \\
\text { dari } 20 \%\end{array}$ & 201 & $50,3 \%$ \\
\hline & & Pengeluaran meningkat 11-22\% & 142 & $35,5 \%$ \\
\hline & & $\begin{array}{l}\text { Pengeluaran meningkat sebesar } \\
5-10 \%\end{array}$ & 47 & $11,8 \%$ \\
\hline & & $\begin{array}{l}\text { Pengeluaran meningkat tidak } \\
\text { lebih dari } 5 \%\end{array}$ & 10 & $2,5 \%$ \\
\hline & & Total & 400 & $100,0 \%$ \\
\hline \multirow{3}{*}{6} & \multirow{3}{*}{$\begin{array}{l}\text { Perubahan } \\
\text { Pekerjaan } \\
\text { Masyarakat }\end{array}$} & Tidak berubah pekerjaan & 323 & $80,8 \%$ \\
\hline & & $\begin{array}{l}\text { Berubah pekerjaan dari } \\
\text { pekerjaan sebelumnya }\end{array}$ & 77 & $19,3 \%$ \\
\hline & & Total & 400 & $100,0 \%$ \\
\hline \multirow{5}{*}{7} & \multirow{5}{*}{$\begin{array}{l}\text { Kondisi Kesehatan } \\
\text { Masyarakat }\end{array}$} & Sering Sakit & 4 & $1,0 \%$ \\
\hline & & Kurang Baik & 32 & $8,0 \%$ \\
\hline & & Baik & 264 & $66,0 \%$ \\
\hline & & Sangat Baik & 100 & $25,0 \%$ \\
\hline & & Total & 400 & $100,0 \%$ \\
\hline \multirow{3}{*}{8} & \multirow{3}{*}{$\begin{array}{l}\text { Penambahan } \\
\text { Fasilitas Pendidikan }\end{array}$} & $\begin{array}{l}\text { Tidak ada penambahan fasilitas } \\
\text { pendidikan }\end{array}$ & 317 & $79,3 \%$ \\
\hline & & $\begin{array}{l}\text { Ada penambahan fasilitas } \\
\text { pendidikan }\end{array}$ & 83 & $20,8 \%$ \\
\hline & & Total & 400 & $100,0 \%$ \\
\hline \multirow{3}{*}{9} & \multirow{3}{*}{$\begin{array}{l}\text { Penambahan } \\
\text { Fasilitas Beribadah }\end{array}$} & $\begin{array}{l}\text { Tidak ada penambahan fasilitas } \\
\text { ibadah }\end{array}$ & 307 & $76,8 \%$ \\
\hline & & Ada penambahan fasilitas ibadah & 93 & $23,3 \%$ \\
\hline & & Total & 400 & $100,0 \%$ \\
\hline \multirow{3}{*}{10} & \multirow{3}{*}{$\begin{array}{l}\text { Penambahan } \\
\text { Fasilitas Kesehatan }\end{array}$} & $\begin{array}{l}\text { Tidak ada penambahan fasilitas } \\
\text { kesehatan }\end{array}$ & 326 & $81,5 \%$ \\
\hline & & $\begin{array}{l}\text { Ada penambahan fasilitas } \\
\text { kesehatan }\end{array}$ & 74 & $18,5 \%$ \\
\hline & & Total & 400 & $100,0 \%$ \\
\hline
\end{tabular}

Tabel 7. Distribusi Frekuensi Dampak perkembangan kawasan Terbangun BerdasarkanAspek Ekonomi di Kota Yogyakarta Tahun 2017

(Sumber: data primer diolah, 2017)

\begin{tabular}{|l|r|r|}
\hline \multicolumn{1}{|c|}{ Kategori } & \multicolumn{1}{c|}{ Jumlah } & \multicolumn{1}{c|}{ Prosentase } \\
\hline Sangat Baik & 38 & 9.5 \\
\hline Baik & 67 & 16.8 \\
\hline Sedang & 148 & 37.0 \\
\hline Buruk & 133 & 33.3 \\
\hline Sangat Buruk & 14 & 3.5 \\
\hline Total & 400 & 100.0 \\
\hline
\end{tabular}

Berdasarkan tabel 7, yang menjawab bahwa terdapat dampak negatif dari perkembangan kawasan terbangun terhadap aspek ekonomi yang diwakili oleh kategori buruk dan sangat buruk yaitu 147 orang $(36,8 \%)$ dan sebanyak 253 orang $(63,2 \%)$ yang menjawab bahwa tidak terdapat dampak negatif terhadap aspek ekonomi yang diwakili kategori sangat baik, baik dan sedang. 


\section{Kesimpulan}

a. Dampak negatif dari perkembangan kawasan terbangun terhadap aspek lingkungan yang diwakili oleh kategori buruk dan sangat buruk dinyatakan oleh responden sebanyak 128 orang $(32,0 \%)$ dan sebanyak 272 orang $(68 \%)$ mewakili pernyataan tidak terdapat dampak negatif terhadap aspek lingkungan yang diwakili kategori sangat baik, baik dan sedang.

b. Dampak negatif dari perkembangan kawasan terbangun terhadap aspek sosial budaya yang diwakili oleh kategori buruk dan sangat buruk dinyatakan oleh responden sebanyak 83 orang $(20,8 \%)$ dan sebanyak 317 orang $(79,2 \%)$ mewakili pernyataan tidak terdapat dampak negatif terhadap aspek sosial budaya yang dikategorikan baik dan sedang. Dampak kawasan terbangun dari aspek sosial budaya tidak terdapat kategori sangat baik $(0 \%)$.

c. Dampak negatif dari perkembangan kawasan terbangun terhadap aspek ekonomi yang diwakili oleh kategori buruk dan sangat buruk dinyatakan oleh responden sebanyak 147 orang $(36,8 \%)$ dan sebanyak 253 orang $(63,2 \%)$ mewakili pernyataan tidak terdapat dampak negatif terhadap aspek ekonomi yang dikategorikan sangat baik, baik dan sedang.

\section{Ucapan Terima Kasih}

Peneliti mengucapkan terima kasih yang sebesar-besarnya kepada Kementrian riset dan pengabdian kepada masyarakat Kemenristek dikti atas pendanaan pada penelitian ini dengan nomer SK 58/STTNAS/P3M/Pen.Dikti/V/2017.

\section{Daftar Pustaka}

Arsyad, L. 1999. Ekonomi Pembangunan. STIE YKPN. Yogyakarta.

BPS Kota Yogyakarta. 2016. Banyaknya Penduduk Menurut Kelompok Umur dan Jenis Kelamindi Kota Yogyakarta, 2013. http://iogiakota.bps. go.id/link TableDinamis/view/id/15. 15 Mei 2016.

BPS Provinsi DIY. 2015. Statistik Daerah Istimewa Yogyakarta 2015.

Jauhari, AgungdanSu Ritohardoyo. 2013. Dampak Pembangunan Perumahan Terhadap Perubahan Penggunaan Lahandan Kondisi Sosial-Ekonomi Penjual Lahan Di Kecamatan Mlati.Volume 2, Nomor 2, Tahun 2013. http://lib.geo.ugm.ac.id/ois/index.php/ibi/article/view/180. 15 Mei 2016

Khairuddin. 2000. Pembangunan Masyarakat: Tinjauan Aspek Sosiologi, Ekonomi dan Perencanaan. Liberty. Yogyakarta.

Kuncoro, M. 2003. Ekonomi Pembangunan, Teori, Masalah dan Kebijaksanaan. UPP AMP YKPN. Yogyakarta.

Munir, B. 2002. Perencanaan Pembangunan Daerah dalam Perspektif Otonomi Daerah. Badan Penerbit Bappeda. Propinsi NTB.

Perda DIY. 2012. TentangRencana Induk Pembangunan Kepariwisataan Daerah Provinsi Daerah Istimewa Yogyakarta Tahun 2012-2025

Riduwan. 2005. Belajar Mudah Penelitian Untuk Guru, Karyawan dan Peneliti Pemula. Alfabeta. Bandung.

Soemarwoto, O. 2001. Ekologi Lingkungan Hidup dan Pembangunan. Djambatan. Jakarta.

Sugiyono. 2011. Metode Penelitian Kuantitatif Kualitatif dan R\&D. Alfabeta. Bandung.

Supriyanta. 2002. Faktor-Faktor Lingkungan Yang Mempengaruhi Penghuni Memilih Lokasi Lingkungan Perumahan Baru Di Kecamatan Depok Kabupaten Sleman Yoyakarta. Tesis Ilmu Lingkungan, UGM Yogyakarta.

Suratmo, Gunarwan. 1993. Analisis Mengenai Dampak Lingkungan. Gadjah Mada Univerity Press. Yogyakarta.

Yuliastuti, Nanydan Arif Fatchurochman.2012.Pengaruh Perkembangan Lahan Terbangun Terhadap Kualitas Lingkungan Permukiman (Studi Kasus: Kawasan Pendidikan Kelurahan Tembalang Vol. 9, No. 1, http://ejournal.undip.ac.id/index.php/ presipitasi/article/view/4806. 15 Mei 2016.

Wardhana, W.A, 2001. Dampak Pencemaran Lingkungan. Penerbit ANDI. Yogyakarta. 